\title{
Active Video Games: Paving the way to Virtual Online Active Games
}

\author{
Dwayne Sheehan ${ }^{2}$, Brian Kooiman ${ }^{1 *}$ and Michael Wesolek ${ }^{1}$ \\ ${ }^{1}$ Clinical Supervisor, Western Governors University, USA \\ ${ }^{2}$ Faculty of Health, Community and Education, Mount Royal University, Canada
}

*Corresponding author: Brian Kooiman, Clinical Supervisor, Western Governors University, 40320 Paseo Del Cielo, Temecula, California 92591, USA

Submission: 海 February 24, 2018; Published: 海 March 20, 2018

\begin{abstract}
Although considerable research has been conducted on playing active video games (AVGs), the majority has focused on proximal play. Little has been reported on distance-based AVG play, identified in this paper as virtual online active games (VOAGs). The potential benefits of VOAGs lies in their ability to connect similar and different populations, genders and generations over the Internet for a new type of gaming in which family, friends, and new acquaintances can participate physically, emotionally, cognitively, and socially when they are at a distance. This paper endeavors to review recent AVG and VOAG literature and illuminate the outcomes associated with playing AVGs and VOAGs to provide suggestions for future research on VOAG. The extension and expansion of what is known about AVGs and VOAGs into probable paths for VOAG research can help to determine if VOAGs are a viable intervention when distance separates participants.
\end{abstract}

Keywords: Exergames; Intergenerational; Distance play; Divergent populations; Video games

\section{Active Video Games: Paving the way to Virtual Online} Active Games

Many forms of technology have been impactful on day-to-day living: computers in the home and workplace, the Internet, smart phones, and smart devices to name but a few. Video games, too, are among the technologies that have introduced significant changes in people's lives, whether in the way they access entertainment, education or physical activity (PA). Rideout et al. [1] report that the time spent playing video games by young Americans between 8 and 18 years increased from 26 minutes daily in 1999 to 73 minutes in 2009. Changes to technology have created a vast network for simultaneous, interconnected play between people in multiple locations. These technologies make physical activity (PA) through game play possible in ways previously not possible. Video games evolve to meet the needs of the consumer so that their creators can generate profits. The continual changes that video games have undergone allow them to attain and retain a popularity that has led to their becoming commonplace in homes of the developed world $[2,3]$. Today's gamers (individuals who self-identify as video game players) prefer to play with family and friends $[2,4]$ and include many women and elderly players [5,6]. Today $47 \%$ of women and $29 \%$ of elderly persons play video games. Seated video game play has been connected to sedentary behaviors but very few who play video games become addicted or violent [7-10]. Indeed, video games, like all technology, can have both positive and negative effects indicating that it may be time to take a closer look at how video games are being used to increase PA and combat sedentary behaviors as the technology progresses [11]. A closer look at a new genre of video game called an active video game (AVG or exergaming) reveals the potential of new video game technologies. AVGs can track body movements and display them on a screen encouraging participants to move from a sedentary position to an active one.

Scientific literature related to AVGs focuses on their potential to improve participants' physical health, to involve them in social activity, to increase motivation to move, and to improve their academic performance [12]. There is a relationship between physical activity and cognitive improvement $[13,14]$. Improved executive functioning skills (a form of cognitive improvement) have also been seen in active gaming studies [13-16]. Additional physical benefits can be realized through the active body movement required by AVGs such as increased physical intensity over sedentary activities [17-24], increased energy expenditure [25-27], improved balance, and physical rehabilitation [28-31]. Participants with physical, social, and emotional disabilities have also derived various health enhancing benefits from playing an AVG [32-35]. These varied populations and outcomes need to be researched for virtual online active games (VOAGs) as well. AVG play can be extended to new settings with Internet connectedness opening the door for the elderly, separated family members, deployed military personnel, and persons with disabilities, to concurrently participate in a VOAG. 
In essence, a VOAG is an AVG that can be played simultaneously by multiple players in different locations. This type of game would allow avatars (character depictions on screen) to be relayed from a gaming device in one location to another device in a remote location for co-operative or competitive play in real time. While VOAG play has been available since the genesis of AVGs, research on VOAGs has lagged behind AVGs played between participants in the same location (proximally).

This lack of research exists because only a few researchers have explored VOAG. This paper endeavors to illuminate the benefits of AVGs and proposes probable concurrent benefits for VOAGs while presenting suggestions for future research. Through a narrative analysis of recent AVG research, the authors present concepts on which to base future studies of VOAGs that can offer a new way to motivate body movement, encourage social interaction, enhance cognitive abilities and reduce sedentary behavior while encouraging participation between and within generations and populations. Finding relevant entertaining ways to encourage movement can help to create a populace that seeks opportunities to engage in movement throughout their life span.

\section{Literature Review}

This literature review presents relevant AVG research from a variety of populations but does not attempt to provide a comprehensive review as others have already done extensive reviews of available literature [36-39]. The purpose of this review is to identify the benefits and problems associated with AVGs so that they can be used to frame the discussion on VOAG and to provide suggestions for future VOAG research. To add clarity to the potentials of AVGs and possible potentials of VOAGs, age groups, gender, and population types are identified. The selection of these groups was guided by the groups found in existing research. Over the past decade an abundance of research has been published in regards to AVGs. The AVG research in this paper focused on recent research from the past five years (2010-2015) allowing for a contemporary treatment of the topic and a focus on the need for future research based upon the potential for VOAGs as a medium for a new way to engage in movement.

\section{Children ages 3-14}

The proclivity of children to play video games [3] may explain why so many researchers have studied the effect of AVGs in this group. Boys and girls who played AVGs with family and friends saw them as a social activity and preferred them to non-active video games $[40,41]$. Additional studies indicate that inactive children may be more apt to play an AVG than to participate in real life activities $[42,43]$ possibly because of a greater perceived chance for success [44] or due to the entertainment value of an AVG. The physical activity component of AVGs is quite possibly the best studied attribute. Pre-adolescent boys expended more energy playing AVGs than when sedentary [45]. White et al. [45] found that energy expenditure was affected by the type of AVG played. For example, bowling resulted in less energy expenditure than dancing. Energy expenditure while playing AVGs is similar to light to moderate physical intensity, making them a healthier alternative to sedentary video game plays $[38,46,47]$. Active Healthy Kids Canada states that children can benefit from exchanging sedentary activities for AVGs which require light to moderate physical intensity [30]. In a large study of elementary aged children engaged in physical education, Sun found that prolonged use of AVGs for two semesters led to increased PA for both boys and girls [48]. These results led Sun to recommend AVGs as a possible method for enhancing PA in physical education. An investigation of middle school students showed that the use of AVGs helped children increase PA levels enough to meet regional and national standards [49]. Another investigation found that children expended more energy while playing AVGs than when resting and sedentary video game play [50].

Ladda [51] identifies a physically literate person as one who is prepared to participate in physical activity throughout their life and shows respect for self $\&$ others [52]. If children are given enjoyable, entertaining activities they will persist in their play leading to greater physical literacy [43]. In one study, 7-11 year old children actually choose AVGs for their perceived health benefits [53]. AVGs have been successfully used in weight management programs to encourage children to increase PA [54,55]. Such programs have resulted in improved Global Self-Worth scores, reduced sedentary screen time, and reduced consumption of soda [56]. AVGs are capable of producing increases in PA [19] but this capability has not translated into long term adherence to PA using AVGs or reduced body mass for healthy gamers $[57,58]$. Special needs populations can benefit from AVG play through the development of motor skills $[30,38]$. Children with cerebral palsy (CP) have shown a benefit from AVG use as a rehabilitative tool $[59,60]$. Children with CP and typically developing children were able to achieve similar levels of physical intensity during AVG play [34,61]. A cycling AVG showed that improvements to aerobic fitness could be achieved for children with CP [32]. Similarly, AVGs helped children with cystic fibrosis achieved light to moderate physical intensity levels [62]. Research results have also shown that AVGs can help children with developmental delays improve their gross motor skills [63]. Appropriately selected AVGs have been credited as being a low cost and easy to obtain piece of technology that can help children achieve light to moderate physical intensity [60,64-66].

\section{Adolescents ages 13-18}

Some authors have found that light to moderate physical intensity levels can be reached by adolescents playing AVGs $[38,47,67]$. Girls who engaged in a dance AVG achieved a moderate level of physical intensity [68] while boys taking secondary physical education classes benefited from AVG play through increased aerobic capacity and enjoyment resulting in a corresponding increase in motivation to play [69]. Increased motivation to play was also noted in a study with overweight and obese African American adolescents that linked higher motivation to play to cooperative AVG game play [70]. In social settings AVGs are preferred over sedentary video games [71]. Overweight and obese participants achieved a lower BMI following AVG use [72]. Increased executive functioning (EF) skills have also been linked to AVGs for adolescents. Success and 
positive engagement while playing an AVG was linked to higher EF while boredom and frustration in movement activities were linked to lower EF scores in a group of African American and Hispanic adolescents [73]. Davis et al. [73] also found that exercise increased executive functioning skills. These studies correlate with a 2010 report by the Centers for Disease Control [14], which connects increased cognitive functioning improvement with physical activity $[74,75]$.

\section{Adults ages 18-54}

Reductions in sedentary behavior were noted for young adults who played AVGs without an increase in energy consumption $[47,76]$. Similarly, sedentary young adults were positively motivated to move at a moderate level of intensity suggesting that AVG play is well suited to serve as an alternative to traditional moderate intensity aerobic activities [47,77]. Worley et al. [27] showed that healthy women may benefit from AVG play by increasing oxygen and caloric demands. University students who are inactive prefer AVGs to the activities offered in Physical Education courses [78]. In a comparison between AVGs and DVD recorded exercise routines, Limperos [79] found that groups of participants viewed AVGs as more motivating and easier to play. When a video game is perceived as an easy to use game and not as a learning task, players are more motivated to engage the game [80]. AVGs that prompt players with an intent to exercise over the intent to play a game can produce more perseverance and longer playing times [81]. However, the emphasis on the health aspects of the game should not override the entertainment value of the game as exercise AVGs that lack entertainment value are less motivating to the players [82]. Obese individuals were motivated to move at a moderate to vigorous level of physical intensity by playing AVGs $[83,84]$. Participants work harder for less perceived effort when they play with a partner virtually over the Internet [85]. These virtual Internet partners can improve the effort and duration of less able partners by their virtual presence and distant silent partner avatars may be able to provide a better form of feedback for increasing length of play than a partner who provides verbal feedback $[85,86]$.

Balance improvement and injury preventions are identified as benefits of AVG balance programs for college students [87]. As for the development of certain motor skills, AVGs have been found to help adults to improve their balance as well [88]. Hurkmans et al. [88] and van den Berg-Emons et al. [89] investigated how adults who suffer from chronic strokes could benefit from AVG play and found that they increased their energy expenditure while playing an AVG. Adults with CP have also been found to increase their physical intensity to a moderate level while playing an AVG [90].

\section{Adults older than 55}

Of all generations, older adults are getting the least amount of PA [91]. Recent statistics have shown that only $12 \%$ of older adults are getting enough strength training for muscle and bone health and only $11 \%$ get enough aerobic activity [92]. This is unfortunate because even moderate levels of PA can help older adults avoid some chronic diseases [93]. In addition to inadequate levels of PA, older adults may also experience social isolation from family and friends [94]. Isolation in older adults can affect physical and mental health resulting in less motivation to engage in movement activities resulting in a negative response to exercise [94]. Older adults were found to be more motivated to exercise and displayed positive gains in socialization following AVG play [95]. The social benefits of such games, for this age group, are evidenced by increased participant enjoyment [96]. It is suggested that innovations are needed to help older adults access and maintain healthy levels of PA [97]. A group of elderly adult subjects were judged to be less likely to fall and exhibit improved health following AVG balance activities [29]. In a similar study AVGs were found to have potential to improve balance when balance was impaired [98]. AVGs have been successful in allowing participants to increase their physical intensity to a light level while seated or while standing [35]. Research has also shown that older adults who are undergoing physical therapy following total knee replacements may use AVGs as acceptable additions to traditional rehabilitative treatments as long as they involve balance for the lower extremities [99].

\section{AVG Strengths Point to VOAG Potential}

There are several researched benefits of AVGs that point to the possible efficacy of VOAGs. Players enjoy AVGs that are competitive or cooperative based upon their personalities [100]. When the AVG type matches the players' preference for task completion they can become more engaged in the PA. Nickel [101] posits that a balance needs to be struck between the cognitive and physical aspect of AVGs so that players receive an appropriately challenging experience that they can achieve given their present skill levels. Research results have shown that AVGs deemed more fun increase the length of participation and energy expenditure during AVG play [102]. When PA is viewed as entertaining, doable, relevant, and enjoyable, players enter into a flow state that result in increased energy expenditure and less perceived effort [103,104]. VOAGs allow for cooperative and competitive play over the Internet with others players enabling participants to engage in PA that expands the pool of participants from proximal to an online community of participants thereby increasing opportunities for participation. AVGs allow players to enter virtual worlds, helping them into flow while playing $[105,106]$. Flow Theory relates to a participants persistence to play [105]. Persistence to play is directly related to the enjoyment levels of the participants. This enjoyment can be gauged by a voluntary desire to play and continued desire to engage in physical activities that are driven by technology $[104,105]$. VOAGs have the added advantage of providing participants with connections to other persons through the Internet increasing chances for PA in a motivating virtual environment even when no one is proximally present to engage them in movement activities.

AVGs use avatars to simulate players on the screen which may benefit those who have body image dissatisfaction by providing players with an alternate view of self while they play [100]. Individuals adhering to a negative body image expressed less anxiety when playing an AVG compared to subjects with a positive body image [100]. The use of typically developed body size avatars 
can help to overcome the lowered desire to move accompanied by the stigma of overweight images [107]. These findings correlate well with additional research which found that participants who more closely associate with their avatar are more motivated to play [108]. Taken together these three studies shed important light on the effect of screen avatars in AVGs. Avatars that positively enhance the image of a player have the potential to increase the benefit of AVG play for overweight and obese players. The virtual nature of VOAGs assures that the benefits mentioned above will also be present for VOAG participants. Technology for improved AVG input allows for game mechanics to more closely resemble real life tasks providing an important bridge between game play and actual movement experiences [101]. This is accomplished when input devices relate absolute position of body parts, such as a camera and infrared sensors that track movement, and not simply relative positions, such as handheld or foot activated input devices [109]. One study found that children with high real life gross motor scores were more successful while playing AVGs [110]. This may indicate a possible positive relationship between improvement in input devices and improvements in player gross motor skills. Another found that differing input devices can be effective when engaging in a VOAG [111].

AVG play lends itself well to use by special populations. Recent research shows that people who are overweight/obese [85], have low body image [100], lack confidence [112], have physical disabilities [90], need rehabilitation activities [30], may all benefit from playing AVGs. One group of researchers studied AVG play between typically developing peers and people with disabilities in wheelchairs and found that wheelchair subjects could participate on par with those who were not in a wheelchair [112]. An activity that allows for enjoyable, engaging energy expenditure for both typically developing and disabled participants shows promise for increased understanding between subjects as well as improved self-esteem for persons with special needs [112]. Persons with disabilities are often isolated by their disability. VOAGs offer this population an opportunity to participate with others over the Internet virtually and show promise for their ability to provide differentiated participation [112].

Some feel AVGs should be used only for the introductory phases of PA training [113]. These investigators state that actual sports will produce more physical intensity than AVGs. A different group of researchers suggest that AVGs can produce an amount of physical intensity similar to that of the actual activity $[113,114]$. This group of researchers state that AVGs may serve as acceptable replacements for traditional activities aimed at increasing physical activities. Persons who are overweight, obese, and have special needs are drawn to virtual PA positioning VOAG play as a way to increase participation among persons in these populations. AVGs are attractive to players of both genders [115]. The ability of AVGs to motivate girls is important because during the transition from adolescence to young adulthood there is a measureable decline in vigorous movement and strengthening activities amongst girls
[116]. This may be due, in part, to the view that girls see themselves as less capable on physical tasks which are competitive in nature; often the core of activities offered in physical education classes [117]. This low view of self has been linked to an increase in the amount of excess weight put on by young women [118]. Given an opportunity to engage in VOAGs female participants may engage the activity with an increased desire to move due to less perceived inequality between participants.

\section{VOAG Research}

While many studies have endeavored to point out the benefits and limitations of AVGs few have taken a look at VOAG those that have point to some encouraging correlations between AVGs and VOAGs. Some have even identified VOAGs for their unique effects on the PA of those who engage them. VOAGs have the ability to link two individuals for competitive, collaborative, or cooperative play over the internet. The Kőhler effect describes the increased effort in less able group members to keep up with the more skilled members of the group. Whilst game system generated non-player characters can elicit the Kőhler effect, stronger Kőhler effect results from play between partners who are thought to be human $[119,120]$. Peng \& Crouse [121] agree that parallel play with another human in a different location is preferred to parallel play in proximity to another human. Similar results were recorded when investigators found that the presence of a proximal peer actually decreased the subjects motivation to play an AVG over a sedentary video game [18]. Additional research shows that heterogenous input devices may be used in VOAG play while retaining social benefits [112]. These intriguing results point to the importance of new VOAG studies to leverage this phenomenon.

VOAGs were studied for their effect on the physical, social, emotional and cognitive changes in secondary physical education students. The results of the research showed that the students enjoyed playing with another student over the Internet more than with a game generated non-player character [122]. Cognitive functioning was increased as measured by executive functioning skills while playing non-player characters and virtually playing another student over the Internet [123]. Motivation to participate was greater for play with another student virtually over the Internet [124]. Heart rate increased more while students engaged another student virtually over the Internet [125]. These initial studies need to be expanded to other generations and within and between other populations such as overweight/obese, special needs, elderly, female and differing social economic groups.

\section{Suggestions for Future VOAG Research}

Although recent research on AVGs is plentiful, in this article we attempted to show that research on VOAGs is still needed. This paper endeavored to present a review of the researched efficacy of AVGs and showed that VOAG play has also been linked to similar results while highlighting the need for future research. VOAGs present opportunities for participation between populations, genders, and generations that are not indicated by AVG research. 
AVGs can be enhanced through internet connections. VOAG play can be beneficial to a variety of groups of people, such as family and children who are separated by distance (i.e.) military personnel, those detained in correctional facilities or when grandparents cannot be with their grandchildren. Likewise, absent parents who must travel or who no longer live with their children may benefit from VOAG play. Additionally, people who lack mobility yet want social interaction; those who prefer the familiarity and security of their own homes yet need encouragement from other players; overweight and obese people who may not enjoy exercising in public but like knowing that others are exercising alongside them; or special needs populations with differing skill levels can all connect for VOAG activities. The VOAG experience may help to make lifelong movers out of increasing numbers of people helping to meet the need for meaningful movement activities that help us connect for play with others in new and relevant ways. The increased motivation that accompanies playing with family and friends, and desire to play longer for less perceived effort, coupled with a need for ways to connect for physical, emotional, social and cognitive play when separated by distance all point to the possible benefit of VOAGs.

\section{References}

1. Rideout VJ, Ulla MA, Foehr UG, Roberts DF (2010) Generation M2: Media in the lives of 8- to 18-year-olds. Henry J Kaiser Family Foundation, Menlo Park, California, USA.

2. Galarneau L (2014) Global gaming stats: Who's playing What, and why?

3. Roberts D, Foehr U, Rideout V (2005) Generation M: media in the lives of 8-18 year olds. The Kaiser Foundation, Menlo Park, California, USA

4. Cole H, Griffiths MD (2007) Social interactions in massively multiplayer online role-playing gamers. Cyberpsychol Behav 10(4): 575-583.

5. Essential facts about the computer and video game industry. Entertainment Software Association.

6. Roy J (2013) Older gamers create their own communities so they don't have to lose to '12-year-old girls from Japan'.

7. Goldfield GS, Kenny GP, Hadjiyannakis S, Phillips P, Alberga AS, et al. (2011) Video game playing is independently associated with blood pressure and lipids in overweight and obese adolescents. PLoS ONE 6(11): e26643.

8. Adachi PJ, Willoughby T (2013) Do video games promote positive youth development? J Adolesc Res 28(2): 155-165.

9. Maillot P, Perrot A, Hartley A (2012) The effects of video games on cognitive aging. Geriatr Psychol Neuropsychiatr Vieil 10(1): 83-94.

10. Oei AC, Patterson, MD (2013) Enhancing cognition with video games: A multiple game training study. PLoS One 8(3): e58546.

11. Gentile DA (2011) The multiple dimensions of video game effects. Child Dev Perspect 5(2): 75-81.

12. Staiano A, Calvert SL (2011) Exergames for physical education courses: Physical, social and cognitive Benefits. Child Dev Perspect 5(2): 93-98.

13. The association between school based physical activity, including physical education, and academic performance.

14. Haapala E (2012) Physical activity, academic performance and cognition in children and adolescents. A systematic review. Baltic Journal of Health and Physical Activity 4(1): 53-61.
15. Best JR (2012) Exergaming immediately enhances children's executive function. Dev Psychol 48(5): 1501-1510.

16. Staiano AE, Abraham AA, Calvert SL (2012) Competitive versus cooperative exergame play for African American adolescents' executive function skills: Short-term effects in a long-term training intervention. Dev Psychol 48(2): 337-342.

17. Ainsworth BE, Haskell WL, Herrmann SD, Meckes N, Bassett DR, et al. (2011) 2011 compendium of physical activities: a second update of codes and MET values. Med Sci Sports Exerc 43(8): 1575-1581.

18. Daley AJ (2009) Can exergaming contribute to improving physical activity levels and Health outcomes in children? Pediatrics 124(2): 763-771.

19. Foley L, Maddison R (2010) Use of active video games to increase physical activity in children: a (virtual) reality? Pediatr Exerc Sci 22(1): 7-22.

20. Mellecker R, McManus A (2008) Energy expenditure and cardiovascular responses to seated and active gaming in children. Arch Pediatr Adolesc Med 162(9): 886-891.

21. Ni Mhurchu C, Maddison R, Jiang Y, Jull A, Prapavessis H, et al. (2008) Couch potatoes to jumping beans: A pilot study of the effect of active video games on physical activity in children. Int J Behav Nutr Phys Act $5(1): 8$.

22. O'Loughlin EK, Dugas EN, Sabiston CM, O'Loughlin JL (2012) Prevalence and correlates of exergaming in youth. Pediatrics 130(5): 806-814.

23. Siegmund LA, Naylor JB, Santo AS, Barkley JE (2014) The effect of a peer on VO2 and game choice in 6-10 year old children. Front Physiol 5: 202.

24. Wittman G (2010) Video gaming increases physical activity. J Ext 48(2): 2.

25. Maddison R, Ni Mhurchu C, Jull A, Jiang Y, Prapavessis H, et al. (2007) Energy expended playing video console games: An opportunity to increase children's physical activity? Pediatr Exerc Sci 19(3): 334-343.

26. Straker L, Abbott R (2007) Effect of screen-based media on energy expenditure and heart ratein 9 to 12 year-old children. Pediatr Exerc Sci 19(4): 459-471.

27. Worley JR, Roger SN, Kraemer RR (2011) Metabolic responses to Wii $\mathrm{Fit}^{\mathrm{TM}}$ video games at different game levels. J Strength Cond Res 25(3): 689-693.

28. Sheehan D, Katz L (2013) The effects of a daily, six week exergaming curriculum on balance in fourth grade children. J Sport Health Sci 2(3): 131-137.

29. Tseng WC, Hsieh RL (2013) Effects of short-term active video game play on community adults: under International Classification of functioning, disability and health consideration. Chin Med J 126(12): 2313-2319.

30. Chaput J, LeBlanc AG, McFarlane A, Colley RC, Thivel D, et al. (2013) Active healthy kids Canada's position on active video games for children and youth. Paediatr Child Health 18(10): 529-532.

31. Middlemas DA, Basilicato J, Prybicien MA, Savoia J, Biodoglio J (2009) Incorporating gaming technology into athletic injury rehabilitation. Athl Train Sports Health Care 1(2): 79-84

32. Knight S, Graham N, Switzer L, Hernandez H, Ye Z, et al. (2015) An innovative cycling exergame to promote cardiovascular fitness in youth with cerebral palsy: A brief report. Dev Neurorehabil 19(2): 135-140.

33. O'Donovan C, Rockhe EF, Hussey J (2014) The energy cost of playing active video games in children with obesity and children of a healthy weight. Pediatr Obes 9(4): 310-317.

34. Robert M, Ballaz L, Hart R, Lemay M (2013) Exercise intensity levels in children with cerebral palsy while playing with an active video game console. Phys Ther 93(8): 1084-1091. 
35. Taylor LM, Maddison R, Pfaeffli LA, Rawstorn JC, Grant N, et al, (2012) Activity and energy expenditure in older people playing active video games. Arch Phys Med Rehabil 93(12): 2281-2286.

36. Barnett A, Cerin E, Baranowsk (2011) Active video games for youth: a systematic review. J Phys Act Health 8(5): 724-737.

37. Guy S, Ratzki AL, Gwadry FS (2011) Moving beyond the stigma: systematic review of video games and their potential to combat obesity. Int J Hypertens.

38. LeBlanc AG, Chaput JP, McFarlane A, Colley RC, Thivel D, et al. (2013) Active video games and health indicators in children and youth: a systematic review. PloS one 8(6): e65351.

39. Lu AS, Kharrazi H, Gharghabi F, Thompson D (2013) A systematic review of health videogames on childhood obesity prevention and intervention. Games Health J 2(3): 131-141.

40. De Vet E, Simons M, Wesselman M (2014) Dutch children and parents' views on active and nonactive video gaming. Health Promot Int 29(2): 235-243.

41. Penko AL, Brakley JE (2010) Motivation and physiologic responses of playing a physically interactive video game relative to a sedentary alternative in children. Ann Behav Med 39(2): 162-169.

42. Boes K, Krell J (2010) Physical activity and motor fitness of children and adolescents- Approaches for serious games. Int J Comput Sci Sport 9(2): 18-26.

43. Sheehan D, Katz L (2010) Using interactive fitness and exergames to develop physical literacy. Physical \& Health Education 76(1): 12-19.

44. Bryan C, Solmon M (2012) Student motivation in physical education and engagement in physical activity. J Sport Behav 35(3): 267-285.

45. White K, Schofield G, Kilding AE (2011) Energy expended by boys playing active video games. J Sci Med Sport 14(2): 130-134.

46. Graf DL, Pratt LV, Hester CN, Short KR (2009) Playing active video games increases energy expenditure in children. Pediatrics 124(2): 534-540.

47. Graves LE, Ridgers ND, Williams K, Stratton G, Atkinson G, et al. The physiologicalcost and enjoyment of Wii Fit in adolescents, young adults, and older adults. J Phys Act Health 7(3): 393-401.

48. Sun H (2013) Impact of exergames on physical activity and motivation in elementary school students: A follow-up study. J Sport Health Sci 2(3) 138-145.

49. Quinn M (2013) Introduction of active video gaming into the middle school curriculum as a school-based childhood obesity intervention. Pediatr Health Care 27(1): 3-12.

50. Smallwood SR, Morris MM, Fallows SJ. Buckley JP (2012) Physiologic responses and energy expenditure of kinect active video game play in schoolchildren. Arch Pediatr Adolesc Med 166(11): 1005-1009.

51. Ladda S (2014) Physical literacy is a social justice issue! JOPHERD 85(5): $3-4$

52. National standards \& grade-level outcomes for K-12 physical education

53. Allsop S, Rumbold PLS, Debuse D, Dodd-Reynolds (2013) Real life active gaming practices of 7-11-year-old children. Games for Health Journal. 2(6): 347-353.

54. Trost SG, Sundal D, Foster GD, Lent MR, Vojta D (2014) Effects of a pediatric weight management program with and without active video games; A randomized trial. JAMA Pediatr 168(5): 407-413.

55. Gao Z, Chen S (2014) Are field-based exergames useful in preventing childhood obesity? A systematic review. Obes Rev 15(8): 676-691.

56. Christison AL, Khan HA (2012) Exergaming for health: a community-based pediatric weight management program using active video gaming. Clin Pediatr (Phila) 51(4): 382- 388.
57. Baranowski T, Abdelsamad D, Baranowski J, O'Conner TM, Thompson D, (2012) Impact of an active video game on healthy children's physical activity. Pediatrics 129(3): e636-e642.

58. Simons M, de Vet E, Brug J, Seidell J, Chinapaw MJ (2014) Active and non-active video gaming among Dutch adolescents - who plays and how much? J Sci Med Sport 17(6): 597-601.

59. Gordon CL, Roopchand-Martin S, Gregg A (2012) Potential of the Nintendo $\mathrm{Wii}^{\mathrm{TM}}$ as a rehabilitation tool for children with cerebral palsy in a developing country: a pilot study. Physiotherap 98(3): 238-242.

60. Howcroft JL, Klejman S, Fehlings D, Wright V, Zabjec K, et al. (2012) Active video game play in children with cerebral palsy: potential for physical activity promotion and rehabilitation therapies. Arch Phys Med Rehabil 93(8): 1448-1456

61. O'Donovan C, Greally P, Canny G, McNally P, Hussey J (2014) Active video games as an exercise tool for children with cystic fibrosis. J Cyst Fibros 13(3): 341-346.

62. Salem YL, Gropack SJ, Coffin D, Godwin EM (2012) Effectiveness of a lowcost virtual reality system for children with developmental delay: a preliminary randomised single-blind controlled trial. Physiotherap 98(3): 189-195.

63. Buschner C (2006) Online physical education: Wires and lights in a box. JOPHERD. 77(2): 3-8.

64. Daum DN, Buschner C (2012) The status of high school online Physical Education in the United States. J Teach Phys Educ 31(1): 86-100.

65. Altamimi R, Skinner G (2012) A survey of active video game literature from theory to technological application. Int J Comp Info Tech 1(1): 2035 .

66. Van Niel CW (2011) Kids can get a workout playing exergames. Pediatrics \& Adolescent Medicine.

67. Fawkner SG, Niven A, Thin AG, Macdonald MJ, Oakes JR (2010) Adolescent girls' energy expenditure during dance simulation active computer gaming. J Sports Sci 28(1): 61-65.

68. West MA (2015) The use of exergames to increase aerobic capacity and motivation and self-efficacy for physical activity in secondary male students in physical education.

69. Staiano AE, Abraham AA, Calvert SL (2012) Motivating effects of cooperative exergame play for overweight and obese adolescents. J Diabetes Sci Technol 6(4): 812-819.

70. Simons M, de Vet E, Hoornstra S, Brug J, Seidell J, et al. (2012) Adolescents' views on active and non-active videogames-a focus group study. Games Health J 1(3): 211-218.

71. Maddison R, Foley L, Ni Mhurchu C, Jiang Y, Jull A, et al. (2011) Effects of active video games on body composition: a randomized controlled trial. Am J Clin Nutr 94(1): 156-163.

72. Flynn, RM, Richert RA, Staiano AE, Wartella E, Calvert SL (2014) Effects of exergame play on EF in children and adolescents at a summer camp for low income youth. J Educ Develop Psychol 4(1): 209-225.

73. Davis CL, Tomporowski PD, McDowell JE, Austin BP, Miller PH, et al. (2011) Exercise improves executive function and achievement and alters brain activation in overweight children: A randomized, controlled trial. Health Psychology 130(1): 91-98.

74. O’Donovan C, Hussey J (2012) Active video games as a form of exercise and the effect of gaming experience: a preliminary study in healthy young adults. Physiotherapy 98(3): 205-210.

75. Easton C, Chaplin H, Christopher CF, Zwygart K, Domene PA, et al. (2012) Impact of an exergame intervention on habitual physical activity and diet in active young adults. American College of Sports Medicine Annual Meeting. 
76. Douris PC, McDonald B. Vespi F, Kelley NC, Herman L (2012) Comparison between Nintendo Wii Fit aerobics and traditional aerobic exercise in sedentary young adults. J Strength Cond Res 26(4): 1052-1057.

77. Vernadakis N, Kouli O, Tsitskari E, Gioftsidou A, Antonious P (2014) University students' ability expectancy beliefs and subjective task values for exergames. Comput Educ 75: 149-161

78. Limperos AM (2014) Are "Wii" Exercising Correctly? Understanding how exergames can be used to increase knowledge of exercise behavior. Games Health J 3(1): 25-30.

79. Shiller SZ, Goodrich K, Gupta PB (2013) Let them play! Active learning in a virtual world. Information Systems Management 30(1): 50-62.

80. Chen FX, King AC, Hekler EB (2014) "Fealthifying” exergames: improving health outcomes through intentional priming. $\mathrm{CHI}$ ' 14 Proceedings of the SIGCHI Conference on Human Factors in Computing Systems, ACM New York, NY, USA 2014: 1855-1864.

81. Lyons EL, Tate DF, Komoski SE, Carr PM, Ward DS (2012) Novel approaches to obesity prevention: effects of game enjoyment and game type on energy expenditure in active video games. J Diabetes Sci Technol 6(4): 839-848.

82. Garn AC, Baker BL, Beasley EK, Solmon MA (2012) What are the benefits of a commercial exergaming platform for college students? Examining physical activity, enjoyment, and future intentions. J Phys Act Health 9(2): 311-318.

83. Siegel SR, Haddock B, Dubois AM, Wilkin LD (2009) Active video/arcade games (Exergaming) and energy expenditure in college students. Int Exerc Sci 2(3): 165-174.

84. Feltz DL, Irwin B, Kerr N (2012) Two-player partnered exergame for obesity prevention: using discrepancy in players' abilities as a strategy to motivate physical activity. J Diabetes Sci Technol 6(4): 820-827.

85. Irwin BC, Feltz DL, Kerr NL (2013) Silence is golden: effect of encouragement in motivating the weak link in an online exercise video game. J Med Internet Res 15(6): 104.

86. Gioftsidous A, Vernadakisa N, Mallioua P, Batziosa S, Sofekleousa P, et al. (2012) Typical balance exercises or exergames for balance improvement? J Back Musculoskelet Rehabil 26(3): 299-305.

87. McConville KM, Valter, J, Virk S (2012) Evaluation of an electronic video game for improvement of balance. Virtual Reality. 16(4): 315-323.

88. Hurkmans HL, Ribbers GM, Streur-Kranenburg MF, Stam HJ, van den Berg, et al. (2011) Energy expenditure in chronic stroke patients playing Wii Sports: a pilot study. J Neuroeng Rehabil 8: 38.

89. Hurkmans HL, van den Ber-Emons RJ, Stam HJ (2010) Energy expenditure in adults with cerebral palsy playing Wii sports. Arch Phys Med Rehabil 91(10): 1577-1581.

90. Ashe MC, Miller WC, Eng JJ, Noreau L (2009) Older adults, chronic disease and leisure-time physical activity. Gerontology 55(1): 64-72.

91. Older Americans 2012: Key indicators of well being

92. 2008 Physical Activity Guidelines for Americans.

93. Cantwell D, Broin DO, Palmer R, Doyle G (2012) Motivating elderly people to exercise using a social collaborative exergame with adaptive difficulty.

94. Chao YY, Scherer YK, Montgomery CA. Lucke KT, Wu YW (2014) Exergames-based intervention for assisted living residents: a pilot study. J Gerontol Nurs 1(7): 36-43

95. Kahlbaugh PE, Sperandio AJ, Carlson AL, Hauselt J (2011) Effects of Playing Wii on well-being in the elderly: Physical activity, loneliness and mood. Activities Adaptation \& Aging 35(4): 331-344.

96. Flora PK, Faulkner GE (2006) Physical activity: an innovative context for intergenerational programming. J Intergener Relatsh 4(4): 63-74.
97. Agmon M, Perry C, Phelan E, Demiris G, Nguyen HQ (2011) A pilot study of wii fit exergames to improve balance in older adults. J Geriatr Phys Ther 34(4): 161-167.

98. Fung V, Ho A, Shaffer J, Chung E, Gomez M (2012) Use of Nintendo Wii $\mathrm{Fit}^{\mathrm{TM}}$ in the rehabilitation of outpatients following total knee replacement: a preliminary randomised controlled trial. Physiotherap 98(3): 183-188.

99. Song H, Kim J, Lee KM (2014) Virtual vs. real body in exergames: Reducing social physique anxiety in exercise experiences. Comput Human Behav 36: 282-285.

100. Nickel A (2013) Designing better exergames: application of flow concepts and the fit principle to full body exertion video games and flexible challenge systems.

101. Mellecker R, Lyons EJ, Baranowski T (2013) Disentangling fun and enjoyment in exergames using an expanded design, play, experience framework: A narrative review. Games Health J 2(3): 142-149.

102. Devereaux J, Pack M, Piccott V, Whitten K, Basset F, et al. (2012) Comparison of rates of perceived exertion between active video games and traditional exercise. International Sportmed Journal 13: 133-140.

103. Monedero J, Lyons EJ, O'Gorman DJ (2015) Interactive video game cycling leads to higher energy expenditure and is more enjoyable than conventional exercise in adults. PLoS ONE 10(3): e0118470.

104. Hansen L, Sanders S (2010) Fifth grade students' experiences participating in active gaming in physical education: The persistence to game. Active Gaming in Physical Education 5(2): 33-40.

105. Klein MJ, Simmers CS (2009) Exergaming: virtual inspiration, real perspiration. Young Consumers 10(1): 35-45.

106. Li BJ, Lwin MO, Younbo J (2014) Wii, myself, and size: the influence of proteus effect and stereotype threat on overweight children's exercise motivation and 'behavior in exergames. Games Health J 3(1): 40-48.

107. Kastenmüller A, Greitemeyer T, Fairclough S, Waite D, Fischer P (2013) Playing exergames and sporting activity the impact of identification with one's game character. Soc Psychol 44(4): 264-270.

108. Thin A, Brown C, Meenan P (2013) User experiences while playing dance-based exergames and the influence of different body motion sensing technologies. International Journal of Computer Games Technology 2013(2013): Article ID 603604.

109. Reynolds JE, Thornton AL, Lay BS, Braham R, Rosenberg M (2014) Does movement proficiency impact on exergaming performance? Hum Mov Sci 34: 1-11.

110. Taiwwo PI, Hwang U, Lee S, Lee C, Yoo Y, et al. (2012) Exer ;ink: Enabling pervasive social exergames with heterogeneous exercise devices. MobiSys.

111. Gerling KM, Miller M, Mandryk RL, Birk MV, Smeddinck JD (2014) Effects of balancing for physical abilities on player performance, experience and self-esteem in exergames.

112. Jenney CT, McKeown B, Dougall L. (2014) Exercise intensity and energy expenditure of a simulated-sport exergame versus real-world sport. Int J Exerc Sci: Conference Proceedings 2(6): Article 52.

113. Perusek K, Sparks K, Little K, Motley M, Patterson S, et al. (2014) A comparison of energy expenditure during "wii boxing" versus heavy bag boxing in young adults. Games Health J 3(1): 21-24.

114. Lieberman DA, Chamberlin B, Medina E, Franklin BA, Sanner BM, et al. (2011) The power of play: innovations in getting active summit 2011: A science panel proceedings report from the american heart association. Circulation 123(21): 2507-2516.

115. Caspersen CJ, Pereira MA, Curran KM (2000) Changes in physical activity patterns in the United States, by sex and cross-sectional age. Med Sci Sports Exerc 32(9): 1601-1609. 
116. Moreno Murcia JA, Coll DC, Ruiz Perez LM (2009) Self-determined motivation and physical education importance. Human Movement 10(1) 5-11.

117. Kimm S, Glynn NW, Obarzanik E (2005) Relation between changes in physical activity and body-mass index during adolescence: a multicentre longitudinal study. Lancet 366(9482): 301-307.

118. Feltz DL, Forlenza ST, Winn B, Kerr NL (2014) Cyber buddy is better than no buddy: A test of the Köhler motivation effect in exergames. Games Health J 3(2): 98-105.

119. Feltz D, Kerr N, Irwin B (2011) Buddy up: The Köhler effect applied health games. J Sport Exerc Psychol 33(4): 506-526.

120. Peng W, Crouse J (2013) Playing in parallel: The effects of multiplayer modes in active video game on motivation and physical exertion. $\mathrm{Cy}$ berpsychol Behav Soc Netw 16(6): 423-427.
121. Kooiman BJ, Sheehan DP (2015) The efficacy of exergames for social relatedness in online physical education. Cogent Education 2(1): 1-15.

122. Kooiman BJ, Sheehan DP (2014) The efficacy of exergames played proximally and over the internet on cognitive functioning for online physical education. American Journal of Distance Education 28(4): 280-291.

123. Kooiman BJ, Sheehan DP (2013) Motivation to move with exergaming in online physical education. International Journal of Physical Education, Fitness and Sports 3(2): 1-24.

124. Kooiman BJ (2013) The efficacy of exergames in a secondary physical education curriculum. Unpublished Dissertation. Cypress, CA. Trident University International.

125. Kooiman BJ, Sheehan DP (2014) Intergenerational remote exergaming with family and friends for health and leisure. Journal of Intergenerational Relationships 12(4).

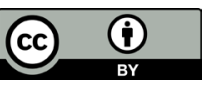

Creative Commons Attribution 4.0

International License

For possible submissions Click Here
Submit Article

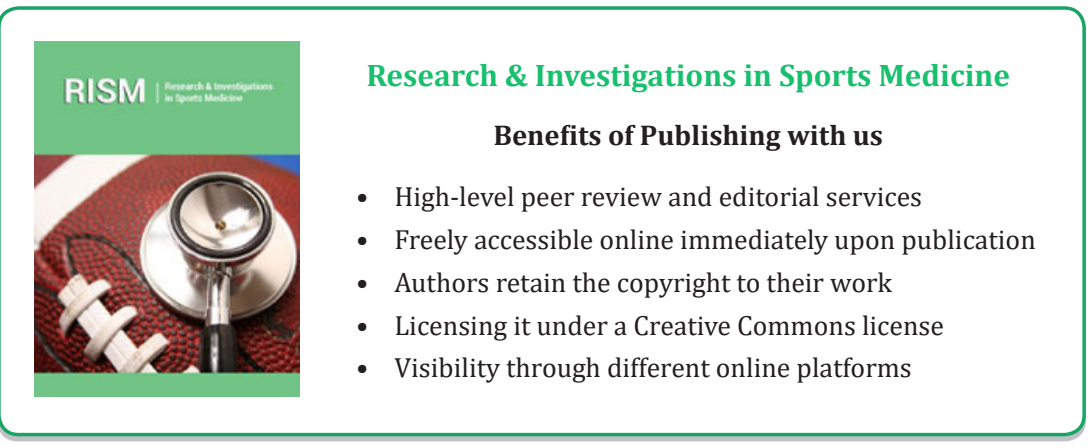

